\title{
The non-linear development of the right hemispheric specialization for human face perception
}

\author{
Aliette Lochy $^{\mathrm{a}, *}$, Adélaïde de Heering ${ }^{\mathrm{b}}$, Bruno Rossion ${ }^{\mathrm{a}, \mathrm{c}}$ \\ a Psychological Sciences Research Institute, Institute of Neuroscience, University of Louvain, Belgium \\ b UNESCOG, Center for Cognition \& Neurosciences, Universite Libre de Bruxelles, Belgium \\ ${ }^{\mathrm{c}}$ Neurology Unit, Centre Hospitalier Regional Universitaire (CHRU) de Nancy, F-54000 Nancy, France
}

\section{A R T I C L E I N F O}

\section{Keywords:}

Face perception

Development

Right lateralization

EEG

\begin{abstract}
A B S T R A C T
The developmental origins of human adults' right hemispheric specialization for face perception remain unclear. On the one hand, infant studies have shown a right hemispheric advantage for face perception. On the other hand, it has been proposed that the adult right hemispheric lateralization for face perception slowly emerges during childhood due to reading acquisition, which increases left lateralized posterior responses to competing written material (e.g., visual letters and words). Since methodological approaches used in infant and children typically differ when their face capabilities are explored, resolving this issue has been difficult. Here we tested 5year-old preschoolers varying in their level of visual letter knowledge with the same fast periodic visual stimulation (FPVS) paradigm leading to strongly right lateralized electrophysiological occipito-temporal face-selective responses in 4- to 6-month-old infants (de Heering and Rossion, 2015). Children's face-selective response was quantitatively larger and differed in scalp topography from infants', but did not differ across hemispheres. There was a small positive correlation between preschoolers' letter knowledge and a non-normalized index of right hemispheric specialization for faces. These observations show that previous discrepant results in the literature reflect a genuine nonlinear development of the neural processes underlying face perception and are not merely due to methodological differences across age groups. We discuss several factors that could contribute to the adult right hemispheric lateralization for faces, such as myelination of the corpus callosum and reading acquisition. Our findings point to the value of FPVS coupled with electroencephalography to assess specialized face perception processes throughout development with the same methodology.
\end{abstract}

\section{Introduction}

Hemispheric lateralization of brain function is well established in humans as well as in other animal species. Yet the reasons for this lateralization are still largely unknown and debated (Corballis, 2009; Davidson and Hugdahl, 1995; Güntürkün et al., 2000). In humans, the right hemisphere $(\mathrm{RH})$ is dominant in the perception of faces of conspecifics, a critical brain function for social interactions. This $\mathrm{RH}$ dominance for face perception has been initially supported by lesion studies, showing that a right ventral occipito-temporal lesion, typically associated with left upper visual field defects, is both necessary and sufficient to cause prosopagnosia, i.e., a severe and selective impairment at individual face recognition (Hecaen and Angelergues, 1962; Meadows, 1974; Sergent and Signoret, 1992; see Davies-Thompson et al., 2014; Rossion, 2014a for reviews). Divided visual field studies and chimeric face effects have also pointed to a right hemisphere advantage in face perception (Gilbert and Bakan, 1973; Hillger and
Koenig, 1991; Kolb et al., 1983; Levy et al., 1972; Rizzolatti et al., 1971), a conclusion largely corroborated over the past two decades by numerous neuroimaging studies (Frässle et al., 2016; Kanwisher et al., 1997; Rossion et al., 2012a; Sergent et al., 1992) and high-density electroencephalographic (EEG) recordings on the human scalp (the right lateralized N170 potential evoked by faces; e.g., Bentin et al., 1996; Rossion and Jacques, 2011 for review). More recently, a strong right hemispheric dominance for face-selective responses in the human ventral occipito-temporal cortex (VOTC) has also been reported with intracerebral electrophysiological recordings (Jonas et al., 2016).

Since the critical brain regions involved in face perception are right lateralized in human adults, understanding when this right hemispheric lateralization emerges during human development and which factors drive this specialization is important to deepen our understanding of human face perception.

de Schonen and Mathivet (1989) initially proposed that the right hemispheric specialization for face perception emerges relatively early

\footnotetext{
* Correspondence to: Psychological Sciences Research Institute, Place Cardinal Mercier 10 bte L3.05.01, 1348 Louvain-la-Neuve, Belgium.

E-mail address: aliette.lochy@uclouvain.be (A. Lochy).
} 
A
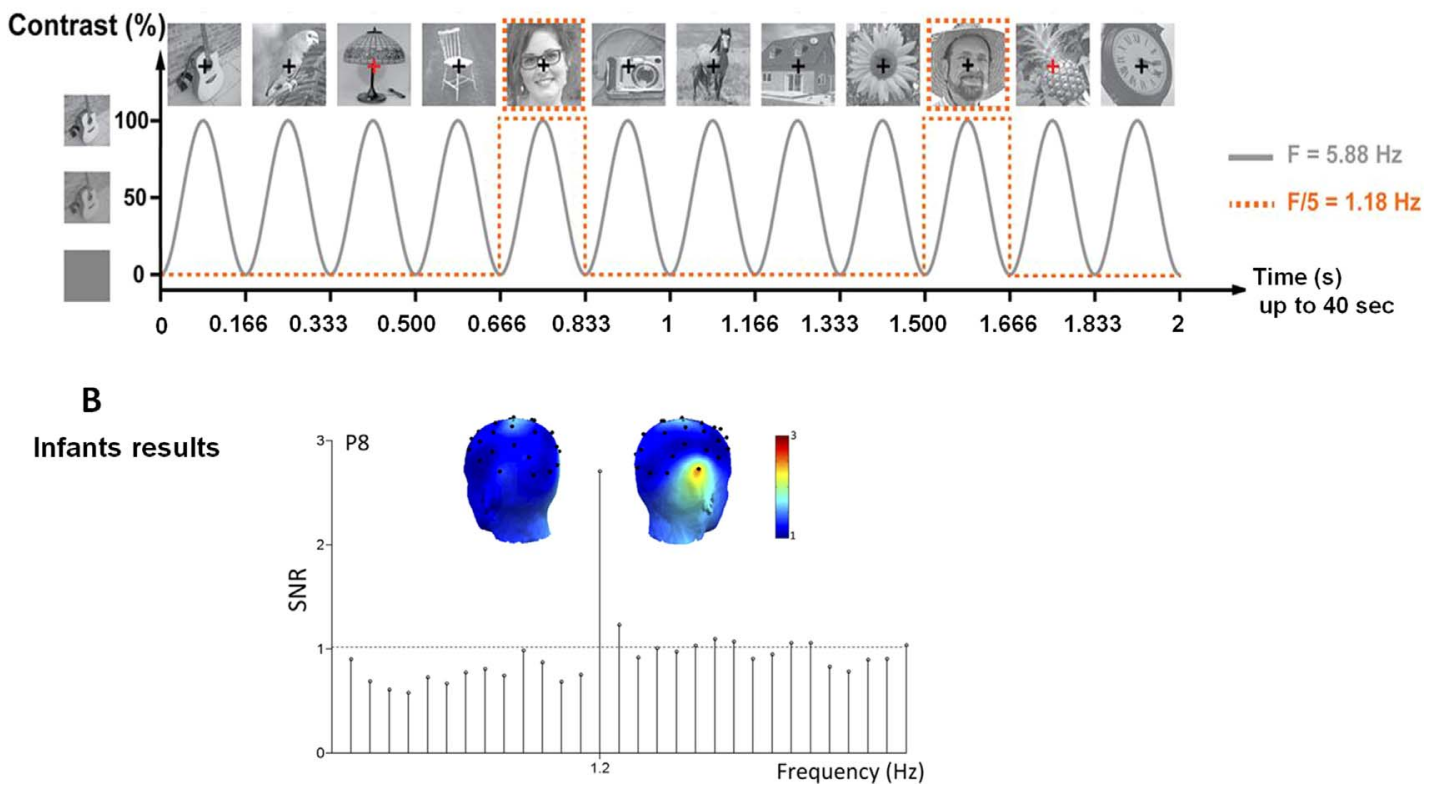

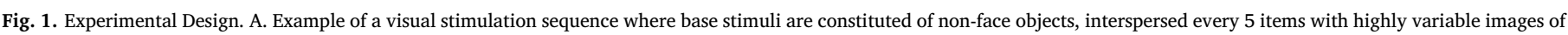

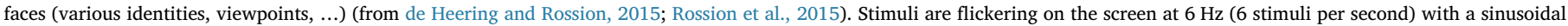

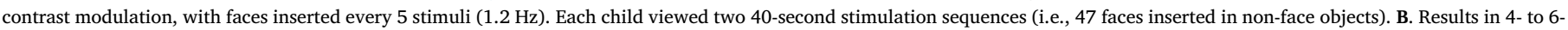

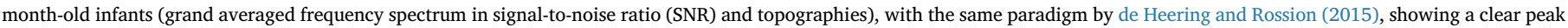
of activation at $1.2 \mathrm{~Hz}$ located on the right occipito-temporal lobe, reflecting generic face categorization.

during development, i.e. being present already at a few months of age. Their proposal was based on the observation that 4- to 9-month-old infants saccade faster towards the picture of their mother's face than the matched picture of a stranger's face when these pictures are presented in the left visual field (LVF) but not in the right visual field (RVF; de Schonen and Mathivet, 1990; de Schonen et al., 1986). Along the same line, right hemisphere but not left hemisphere early deprivation of visual input for several months (between 6 weeks and 3 years) impairs the development of the adult expert (i.e., holistic/configural) face processing system (Le Grand et al., 2003). At the neural level, some studies using functional near-infrared spectroscopy (fNIRS) have also shown a significant RH advantage for faces over control visual stimuli in 5- to 8-month-old infants (e.g., Otsuka et al., 2007; see Otsuka, 2014 for a review). More recently, de Heering and Rossion (2015) exposed 4to 6-month-old infants to numerous and highly variable natural images of faces inserted periodically ( 1 out of 5$)$ in a fast $(6 \mathrm{~Hz})$ stream of nonface object images while recording their electroencephalogram (EEG) (Fig. 1A). Strikingly, infants' face-specific response to the frequency at which faces were presented in the sequence $(1.2 \mathrm{~Hz}=6 \mathrm{~Hz} / 5)$ was the largest over their right occipito-temporal cortex (Fig. 1B). Importantly, this specific response to faces was not found for phase-scrambled images, ruling out potential low-level visual accounts of the effect (de Heering and Rossion, 2015).

Altogether, these observations support de Schonen and Mativet's hypothesis that the right hemisphere takes precedence over the left hemisphere at an early age, which might be the result of its faster maturation rate at a time at which the infants' visual system mainly extract low spatial frequencies, and therefore global information, from facial inputs (Sergent, 1982).

However, according to a recent hypothesis, the right hemispheric specialization for face perception would rather emerge relatively late during development, i.e. when children learn to read, and would gradually increase through adolescence (Behrmann and Plaut, 2015; Dundas et al., 2012; see also Dehaene et al., 2015). This hypothesis generally rests on the general view that right hemispheric specialization for faces - and of other functions such as spatial perception - follows the left lateralization for language functions (Corballis, 1991; Lhermitte et al., 1972). More specifically, it states that the right hemisphere becomes dominant for face perception due to the gradual specialization of the left VOTC after children's exposure to a written script during reading acquisition. This specialization would then compete with the representation of faces in the left hemisphere, resulting in face representations mainly located in the RH (Behrmann and Plaut, 2015). This view is supported by several findings. First, the behavioral left visual field advantage caused by the RH superiority for face processing correlates positively with reading competence in school children and young adolescent (Dundas et al., 2012). Second, children of 9-12 years of age show a positive correlation $\left(\mathrm{r}^{2}=0.32\right)$ between the amplitude of the left N170 for words and the right N170 for faces, although the N170 for faces is not significantly stronger in the right hemisphere (Dundas et al., 2014) Third, literacy changes the hemispheric balance of neural response to faces with a slight decrease of neural activity in the left fusiform gyrus and a clearer increase in the homologous area of the right fusiform gyrus (in adults: Dehaene et al., 2010; and 10-year-old children: Monzalvo, Fluss, Billard, Dehaene, and Dehaene-Lambertz, 2012; respectively). Finally, left-handed individuals, who as a group show greater variability with respect to hemispheric language dominance than right-handed individuals, also show greater variability in their degree of RH lateralization of faces as evidenced from both behavioral (Dundas et al., 2015) and neural measurements (fMRI: Bukowski et al., 2013; Frässle et al., 2016; EEG: Dundas et al., 2015).

In sum, there is a striking contrast between evidence collected in young infants, supporting the early emergence of a $\mathrm{RH}$ lateralization for face perception independent of reading acquisition, and evidence gathered from children, adolescents and adults, rather favoring a late and gradual $\mathrm{RH}$ lateralization of face perception emerging as a consequence of reading acquisition and reading skills.

So far, these views, based on different sets of evidence, have been difficult to reconcile. The major reason for this difficulty is that studies in infants and children have been conducted with different techniques and paradigms. For instance, while fNIRS, visual field dominance paradigms and visual preference/adaptation paradigms have been 
generally used to test infants, fMRI and explicit behavioral tasks in divided visual field presentations have rather been used with children. Second, even with a technique readily applicable in both infants and children/adults such as the recording of event-related potentials (ERPs) in EEG, responses in the time-domain remain difficult to quantitatively compare across populations. For instance, the occipito-temporal N170 found in adults and also children from 5 years of age (Itier and Taylor, 2004a; Kuefner et al., 2010), is not observed in young infants, in which ERP components to faces peak later and over medial occipital sites, without hemispheric lateralization (i.e., the N290, de Haan and Nelson, 1999; de Haan et al., 2002; Gliga and Dehaene-Lambertz, 2007; Hoehl and Peykarjou, 2012).

The main objective of the present study is to start filling this gap in our knowledge by applying the exact same paradigm of de Heering and Rossion (2015) showing right lateralized face-selective responses in 4to 6-month-old infants to a population of 5-year-old preschool children. Using the same paradigm in infants and young children appears as the most fruitful approach to assess whether the non-linearity in face perception development suggested by the above-reviewed studies is genuine, or whether these discrepant results are only the consequence of using different approaches for testing infants vs. young children.

At many levels, this Fast Periodic Visual Stimulation (FPVS; Rossion, 2014a) approach combined with EEG appears ideally positioned to shed light on the origin and the developmental course of face perception and of its RH lateralization. First, FPVS leads to the recording of high signalto-noise ratio brain responses which can be identified objectively in the frequency domain after Fourier Transform and are usually termed "Steady-State Visual Evoked Potentials" (SSVEPs, after (Regan, 1989, 1966); see Norcia et al., 2015 for review). Hence, this approach has been used in classical infant studies to inform about early development of primary visual functions (e.g., Braddick et al., 1986; Norcia et al., 1988). Second, it does not require an explicit face processing task, which might be contaminated by motivational or decisional factors that are particularly difficult to control in young individuals, and differ greatly across development. Third, it leads to electrophysiological responses that can be directly quantified at the individual level, allowing to test relationship between these responses and behavioral measures in children for instance (e.g., Lochy et al., 2016). Finally, and more specifically, this approach has been recently successfully extended to capture high level face categorization responses in adults (e.g., LiuShuang et al., 2014; Rossion et al., 2015).

Using this approach, the first goal of the present study was to test whether the right hemispheric lateralization of face-selective responses observed in 4-6 months old infants is also observed in preschool children. Since the face-selective response obtained in this paradigm is right lateralized in both infants and adults, we hypothesized a right lateralization in children, supporting the idea of an early emergence and stability of the right hemispheric dominance for face perception. This finding would show that the discrepancy of the results obtained so far are the consequence of using different approaches for testing infants vs. young children. Alternatively, if our results reveal bilateral responses for faces in children, as suggested by studies using other paradigms at this age, it would then rather point to a genuine nonlinear development of the neural processes underlying face perception.

The second goal of this study was to examine the potential relationship between early reading acquisition and lateralization of the response to faces in preschoolers. Thus, we targeted specifically children of that age range because they have not been exposed to formal reading acquisition, yet they show variable knowledge of visual letters, which already drives an early left hemispheric lateralization for this material in FPVS-EEG (Lochy et al., 2016). Since the current group of preschoolers had also been tested in a previous study with orthographic material (Lochy et al., 2016), we examined the potential relationship between letter knowledge, left lateralization of the response to letters, and lateralization of the response to faces. Based on the literature, we expected a positive relationship between the left lateralization to letters and the right lateralization to faces (i.e., a further increase of right lateralization for faces in children with higher letter knowledge; Dehaene et al., 2015).

\section{Material and methods}

\subsection{Participants}

The data of thirty-four children ( 20 males, mean age $=5.51$ years; range $=5.01-5.94$ years), with normal/corrected-to-normal vision, was collected after the parents gave their informed consent for the study approved by the Biomedical Ethical Committee of the University of Louvain (Belgium). Children were unaware of the goal of the experiment and that a change of stimulus type occurred at a periodic rate during stimulation. These children were part of a larger sample tested in a visual letter discrimination experiment that revealed a specific response for letters (words or pseudo-words) among pseudo-letters in the left hemisphere (O1) that also correlated with their letter knowledge (Lochy et al., 2016). They underwent a screening battery with subtests of the WISC-R, visuo-attentional capacities, vocabulary, and reading abilities.

\subsection{Stimuli}

Two-hundred and fifty images of various objects (animals, plants, man-made objects) and 50 images of faces, collected from the internet, were used, as in previous studies (de Heering and Rossion, 2015; Rossion et al., 2015). They differed in terms of viewpoint, lighting conditions and background (Fig. 1A). They were all resized to $200 \times$ 200 pixels, equalized in terms of luminance and contrast in Matlab (Mathworks), and shown in the center of the screen at a $800 \times 600$ pixel resolution. At a testing distance of $40 \mathrm{~cm}$, they subtended approximately 13 by 13 degrees of visual angle.

\subsection{Procedure}

Stimulation was virtually identical to the study of de Heering and Rossion (2015) in infants, except for the duration of stimulation sequences (20 s in infants, $40 \mathrm{~s}$ in the current study) and their number (variable in individual infants). Each stimulation sequence started with a fixation cross displayed for $2-5 \mathrm{~s}$, $2 \mathrm{~s}$ of stimulation fade-in, $40 \mathrm{~s}$ of stimulation sequence, and $2 \mathrm{~s}$ of gradual fade-out. Stimuli were presented through sinusoidal contrast modulation at the base frequency rate of $6 \mathrm{~Hz}$ (i.e., one item every $166.66 \mathrm{~ms}$, hence each item reached full contrast after $83 \mathrm{~ms}$ ) (Fig. 1A). Given that the stimulus can be recognized at very low contrast (i.e., $20 \%$ or less), the actual duration of stimulus visibility approximates $140 \mathrm{~ms}$.

Every sequence followed the same structure, namely: base stimuli (non-face objects, O) were presented at $6 \mathrm{~Hz}$, with a deviant stimulus of the category of interest (faces, F) introduced every fifth item $(1.2 \mathrm{~Hz}$, thus every $833 \mathrm{~ms}$ ) such as: OOOOFOOOOFOOOOF... (Fig. 1A). MATLAB 7.8 (The Mathworks) with PsychToolbox ((Brainard, 1997) see http://psychtoolbox.org/) was used for stimulus display. Since this approach provides a very high signal-to-noise ratio (SNR), even in young infants (de Heering and Rossion, 2015), only two 40 s sequences were used here. Each stimulation sequence was initiated manually after ensuring low-artifact EEG signals. During stimulation, children fixated a central cross and were instructed to press the space bar for any brief $(200 \mathrm{~ms})$ color change of the fixation cross (blue to red; 6 changes randomly timed per sequence). The goal of this orthogonal task was to maintain their level of attention as constant as possible throughout the experiment. Children performed this task almost at ceiling (mean: 90\%; SE: 0.02), showing high attention to the stimuli presented on the screen, with average response times of $733 \mathrm{~ms}$ (SE: 17.08). 


\subsection{EEG acquisition and preprocessing}

Children were seated comfortably at $1 \mathrm{~m}$ from the computer screen in a quiet room of the school. EEG was acquired at $1024 \mathrm{~Hz}$ using a 32channel Biosemi Active II system (Biosemi, Amsterdam, Netherlands), with electrodes including standard 10-20 system locations (http:// www.biosemi.com). The magnitude of the offset of all electrodes, referenced to the common mode sense (CMS), was held below $50 \mathrm{mV}$. All EEG analyses were carried out using Letswave 5 (http://nocions. webnode.com/letswave), and Matlab 2012 (The Mathworks) and were virtually identical to analyses performed on the same type of data collected in adults (Rossion et al., 2015) and infants (de Heering and Rossion, 2015). After FFT band-pass filtering around 0.1 and $100 \mathrm{~Hz}$, EEG data were segmented to include $2 \mathrm{~s}$ before and after each sequence, resulting in 44-second segments ( -2 to $42 \mathrm{~s}$ ), to allow for a better visualization of the epochs per condition and for potential artifacts detection before re-referencing. Data files were then resampled to $250 \mathrm{~Hz}$ to reduce file size and data processing time. Artifact-ridden or noisy channels were replaced using linear interpolation (no more than two electrodes for each participant). All channels were re-referenced to the common average. EEG recordings were then segmented again from stimulation onset until $39.996 \mathrm{~s}$, corresponding exactly to 48 complete $1.2 \mathrm{~Hz}$ cycles within stimulation. This value corresponds to the largest amount of complete cycles of $833 \mathrm{~ms}$ at the face stimulation frequency $(1.2 \mathrm{~Hz})$ within the $40 \mathrm{~s}$ of stimulation period.

\subsection{Frequency domain analysis}

The two trials were averaged in the time domain for each individual participant, in order to increase the signal-to-noise ratio (SNR). A Fast Fourier Transform (FFT) was applied to this averaged time-window, and normalized amplitude spectra were extracted for all channels. This yielded EEG spectra with a high frequency resolution $(1 / 39.996 \mathrm{~s}=$ $0.025 \mathrm{~Hz}$ ), increasing SNR (Rossion, 2014b) and allowing unambiguous identification of the response at the exact frequencies of interest (i.e., $6 \mathrm{~Hz}$ for the base stimulation rate and $1.2 \mathrm{~Hz}$ and its harmonics for the face stimulation). To estimate SNR across the EEG spectrum, amplitude at each frequency bin was divided by the average amplitude of 20 surrounding bins (10 on each side) (Rossion et al., 2012b). These SNR measurements were computed for display of the response spectra. To provide a quantitative measure of the responses in microvolts, a noisecorrected amplitude was computed, where the average voltage amplitude of the 20 surrounding bins (i.e., the noise) was subtracted out (Retter and Rossion, 2016). Finally, in order to identify significant harmonics, Z-scores were computed based on the grand-averaged amplitude spectrum at every channel. This allowed to assess the significance of the response at the face stimulation frequency and harmonics, and at the base rate and harmonics (Lochy et al., 2015; LiuShuang et al., 2014). Z-scores were calculated for each discrete frequency bin ( $\mathrm{x}$ ) according to the following formula: $\mathrm{Z}=$ (x-noise mean)/ (noise standard deviation), where the noise was defined as the 20 frequency bins surrounding each target bin and excluding the immediately adjacent bins and the local maximum and minimum amplitude bins. ZScores larger than $1.64(\mathrm{p}<0.05$, one-tailed, signal $>$ noise $)$ were considered as significant. The face-selective response was significant up to $10.8 \mathrm{~Hz}$ ( 9 harmonics), and the base-rate response was significant up to $36 \mathrm{~Hz}$ (6 harmonics). Finally, the noise subtracted amplitudes of significant harmonics (excluding the base stimulation frequency) were summed for each participant to quantify the periodic response distributed on several harmonics (Retter and Rossion, 2016).

In order to assess the significance of responses in individual participants, we first summed the amplitude values of the harmonics significant at the group-level (from $1.2 \mathrm{~Hz}$ to $10.8 \mathrm{~Hz}$ excluding the base rate). Then, for each participant, we computed individual Z-scores on these sums of harmonics, which we considered as significant only if they were larger than 1.64 .

\subsection{Relationship between letter and face processing}

In order to relate preschoolers face-specific responses (here) to their neural tuning to letters as well as their letter knowledge, we extracted their behavioral measures of reading, as well as their neural responses to letters from a previous study (Lochy et al., 2016). In this study, the same paradigm was used with base stimuli at $6 \mathrm{~Hz}$ stimulation frequency constituted of pseudo-letters and deviant stimuli at $1.2 \mathrm{~Hz}$ stimulation frequency constituted of letter-strings. Two measures of letter knowledge were considered: production of grapheme-phoneme correspondences (number of correctly named letters upon written presentation, BELO task; George and Pech-Georgel, 2006), and recognition of grapheme-phoneme correspondences (number of correctly chosen written letters in a multiple-choice display, when a letter was orally named by the experimenter).

Since the amplitudes are already normalized by the noise subtraction procedure mentioned above, we computed lateralization scores (LS: RH-LH), rather than lateralization indexes (LI: RH-LH/RH + LH), by subtracting the amplitude values of the left hemisphere (LH) from values of the right hemisphere $(\mathrm{RH})$ both for responses to letters and to faces. Positive and negative values indicate a right and a left lateralization respectively. We focused on 2 regions-of-interest - the left occipito-temporal cortex (LOT $=\mathrm{O} 1, \mathrm{P7}, \mathrm{PO} 3$ ) and the right occipitotemporal cortex (ROT $=\mathrm{O} 2, \mathrm{P} 8, \mathrm{PO} 4)$, as well as on 2 electrodes-ofinterest associated with the strongest responses, located at the dorsal site for faces: $\mathrm{PO} / \mathrm{PO} 4$ (see Section 3); and posterior site for letters: O1/O2 (see Lochy et al., 2016).

\section{Results}

Scalp topographies and EEG spectra of preschoolers' grand-averaged data showed a clear (i.e., SNR $>2,>100 \%$ increase of signal; sum of noise-corrected amplitudes $>4 \mu \mathrm{V}$ ) face-selective response at $1.2 \mathrm{~Hz}$ as well as at its harmonics $(2.4 \mathrm{~Hz}, 3.6 \mathrm{~Hz}$, up to $10.8 \mathrm{~Hz})$ on posterior electrodes (Fig. 2). Unexpectedly, i.e. contrary to infants (de Heering and Rossion, 2015; see Fig. 1A) and adults (Rossion et al., 2015), preschoolers did not show any RH lateralized face-selective brain response (Fig. 2).

The sum of noise corrected amplitudes was computed for each participant on 9 harmonics excluding the base rate $(1.2 \mathrm{~Hz}$ to $10.8 \mathrm{~Hz})$ as determined by grand-averaged data $(\mathrm{F} / 5-9 \mathrm{~F} / 5)$ (maximal number of consecutive harmonics with a Z-score $>1.64$ ). The largest responses were recorded at electrodes PO3-PO4, O1-O2, and P7-P8 (the left electrodes PO3, P7 and $\mathrm{O} 1$ and the right electrodes PO4, P8, and $\mathrm{O} 2$ are grouped into left and right ROI for purpose of display in Fig. 2). A $2 \times 3$ repeated measures ANOVA with Hemisphere (left, right) and Electrode Site (posterior (O1/O2), lateral (P7/P8), and dorsal (PO3/PO4)) as within-subject factors was conducted on participants' sum of noise corrected amplitudes. There was a significant effect of Electrode Site [F $(2,66)=4.938 ; \mathrm{p}<0.01]$, with brain responses being stronger at dorsal sites (PO3/PO4, $4.011 \mu \mathrm{V}, \mathrm{SE} 0.308$ ) than at lateral or posterior sites (P7/P8: $2.9 \mu \mathrm{V}, \mathrm{SE}=0.305$; O1/O2: $3.423 \mu \mathrm{V}, \mathrm{SE}=0.265$ ). There was no effect of Hemisphere $[\mathrm{F}(1,33)<1](3.428 \mu \mathrm{V}$, $\mathrm{SE}=0.226$ and $3.461 \mu \mathrm{V} \mathrm{SE}=0.291$ for $\mathrm{LH}$ and $\mathrm{RH}$ respectively) and no interaction between the two factors $[\mathrm{F}(2,66)=2.750 ; \mathrm{p}=0.08]$. Crucially, we did not find any significant difference between the 2 hemispheres at any of the electrode sites (dorsal, lateral, posterior) considered into the analyses (all ps $>0.15$; O2-O1 $=0.065 \mu \mathrm{V}$; P8-P7 $=0.639 \mu \mathrm{V}$; PO4-PO3 $=-0.607 \mu \mathrm{V})$. Paired comparisons confirmed that brain responses were significantly stronger at dorsal sites $(\mathrm{PO} / \mathrm{PO} 4)$ than at lateral $(\mathrm{P} 7 / \mathrm{P} 8)(\mathrm{p}<0.007)$ or posterior $(\mathrm{O} 1 / \mathrm{O} 2)(\mathrm{p}<0.04)$ sites. Lateral and posterior sites did not differ $(\mathrm{p}=0.18)$.

Importantly, the face-selective response was significant in every individual child tested on at least two electrodes among the 6 electrodes considered in these ROIs, as revealed by Z-scores $(\mathrm{p}<0.05)$. Almost half of the participants $(\mathrm{N}=16)$ had a significant response on all 6 


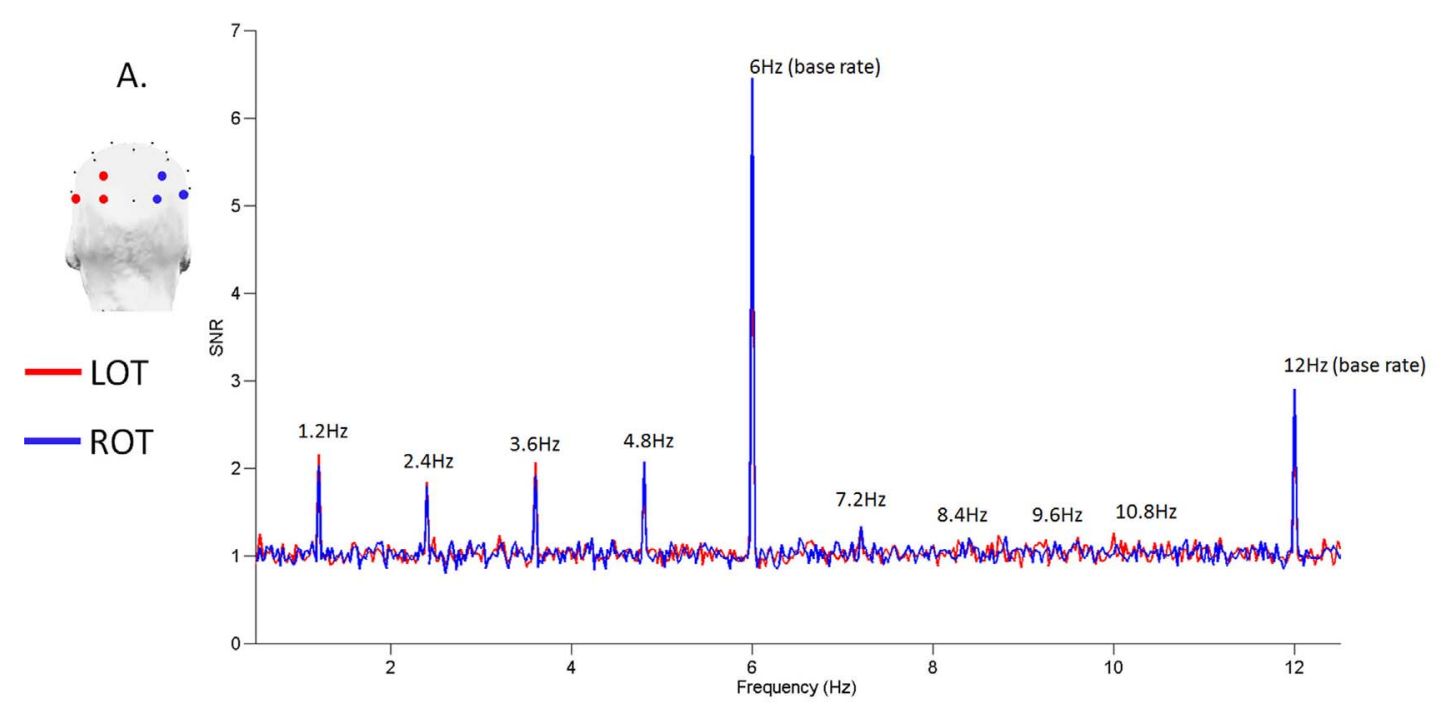

B. Face-selective response

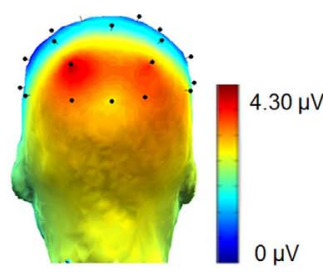

C. Base rate response

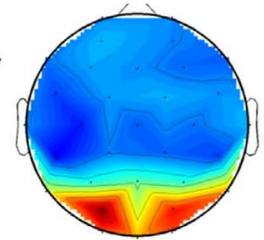

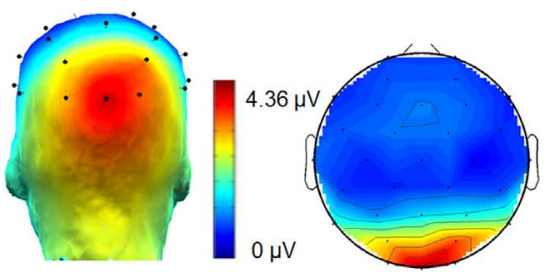

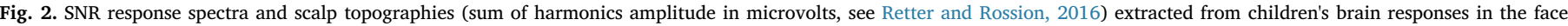

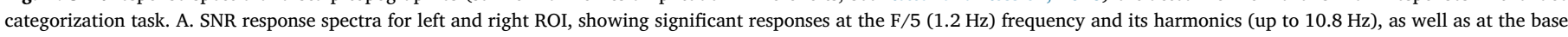

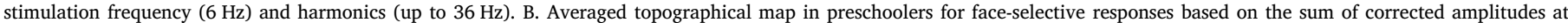

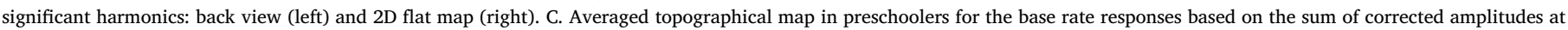
significant harmonics: back view (left) and 2D flat map (right).

posterior channels. Even with a more stringent statistical criterion of $\mathrm{p}<0.001$ ( $\mathrm{Z}>3.1$ ), more than half of the participants still displayed a significant face-selective response on most of the 6 posterior channelsof-interest, and 28 out of 35 on channel PO3.

Contrary to this face-selective response, the base rate response displayed a medial occipital topography (see Fig. 2C), and displayed the highest amplitude value on $\mathrm{Oz}(4.314 \mu \mathrm{V})$, followed by $\mathrm{O} 1(3.198 \mu \mathrm{V})$ and $\mathrm{O} 2(3.583 \mu \mathrm{V})$. We analyzed responses at and around $\mathrm{Oz}$ with a one-way ANOVA with 3 levels of electrodes: O1-Oz-O2 followed by paired $t$-tests. There was a significant effect of electrodes $[\mathrm{F}(2,64)=$ 8.745; $\mathrm{p}<0.000]$. Oz response was significantly higher than both what was recorded on $\mathrm{O} 1(\mathrm{p}<0.0001)$ and $\mathrm{O} 2(\mathrm{p}<0.004)$; but responses on $\mathrm{O} 1$ and $\mathrm{O} 2$ did not significantly differ $(\mathrm{p}=0.248)$.

Next, we correlated the lateralization scores for faces to preschoolers' behavioral measures (Fig. 3A). Testing our second hypothesis, we found that children's letter recognition scores were modestly but significantly correlated with their lateralization score on the dorsal electrode site $\mathrm{PO} / \mathrm{PO} 4$ showing the largest response (Spearman rho $=$ 0.296; $p=0.045$ ), with a non-significant trend on the ROI lateralization score (ROT-LOT) (Spearman rho $=0.256 ; \mathrm{p}=0.072$ ). That is, the right lateralization for faces increased with the number of letters recognized by the children. However, letter production did not correlate with the lateralization score for faces on PO3/PO4 (rho $=0.179 ; \mathrm{p}=$ 0.156 ) or on the ROI (ROT-LOT) (rho $=0.175 ; \mathrm{p}=0.162$ ). Note that these two behavioral measures correlated negatively with the lateralization score for letters on 01/O2 (production: rho $=-0.335 ; \mathrm{p}=$ 0.026; and recognition, rho $=-0.428 ; \mathrm{p}=0.006$, Fig. $3 \mathrm{~B}$ ), where the response to letters contrasts maximally, and was used as the letter discrimination response in (Lochy et al., 2016). This replication of a significant correlation with another analysis approach, i.e., using a lateralization score rather than the raw amplitude in the LH as in (Lochy et al., 2016), confirms that the more known letters, the more the LH responds selectively to letter-strings.

Finally we assessed whether the brain responses to letters and to faces were negatively correlated, that is, whether the more left lateralized the response to letters and the more right lateralized the response to faces. This analysis led to non-significant results as revealed by the non significant correlation between lateralization scores in the two types of discriminations (letters vs. faces) whether on ROIs (ROT-LOT) (Spearman rho $=-0.166 ; \mathrm{p}=0.174$ ) or on electrodes with largest responses in each type of discrimination (O2-O1 for letters and PO4PO3 for faces) (Spearman rho $=-0.122 ; \mathrm{p}=0.245$ ).

\section{Discussion}

Thanks to the same FPVS-EEG paradigm previously used in adults (Liu-Shuang et al., 2016; Rossion et al., 2015) and in infants (de Heering and Rossion, 2015), we found a robust face-selective electrophysiological bilateral response in 5-year-old preschoolers. We also observed a positive relationship between the number of letters known by each child, as assessed by a letter recognition task, and their brain right lateralization for faces as assessed with a lateralization score. There was, however, no relationship between the degree of their left brain lateralization to letters and the right lateralization to faces.

The face-selective response, indexing face categorization, was obtained in a few minutes of recording only and was significant in all individual participants on at least two electrodes in the regions of interest (i.e., left and right occipito-temporal regions). This response reflects a real high-level perceptual categorization process: while the common response to faces and objects projects to a common $6 \mathrm{~Hz}$ base rate response, the $1.2 \mathrm{~Hz}$ frequency response and its harmonics appear only if children discriminate face images from a wide variety of nonface 

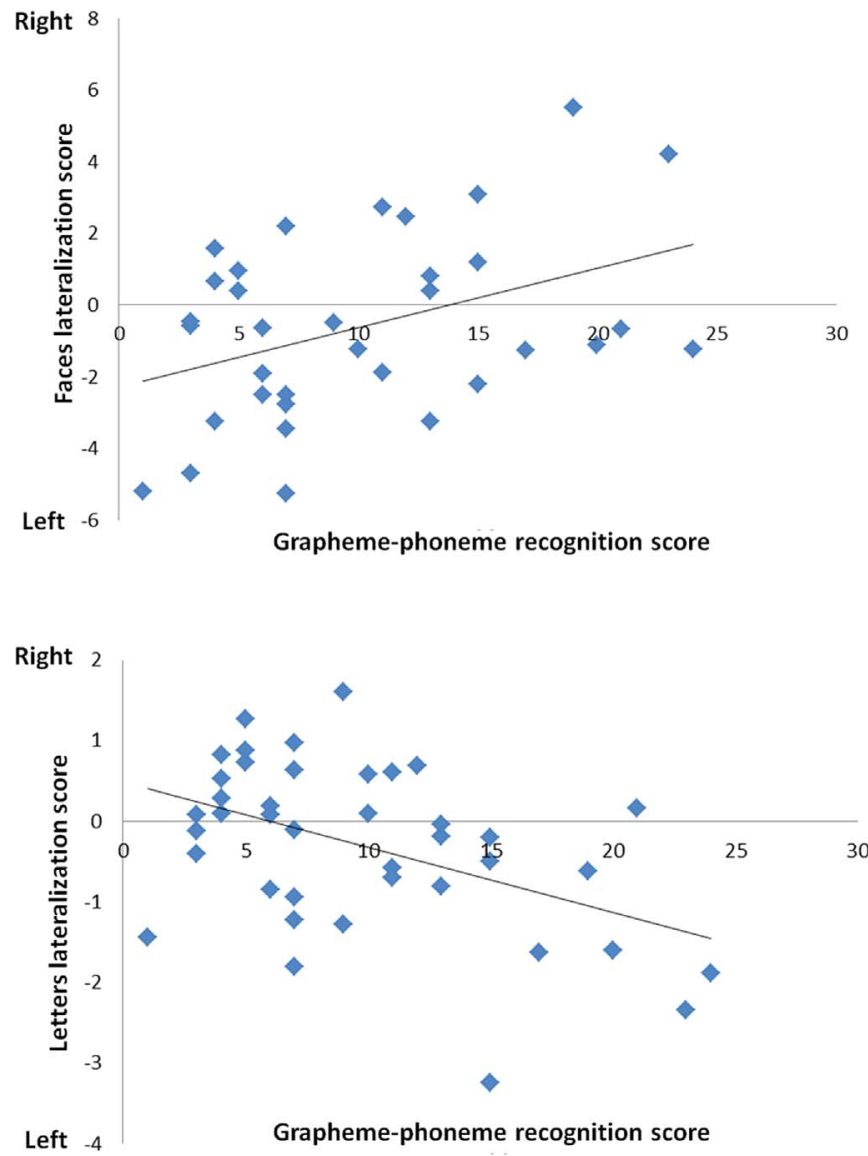

Fig. 3. Scatter plots suggesting a significant relationship between preschoolers' behavioral reading performance indexed through grapheme-phoneme (GP) recognition scores and their brain lateralization scores. A. Positive correlation (rho $=0.29$ ) between GP recognition and $\mathrm{RH}$ lateralization score for faces (difference between amplitude at PO4 (RH) and amplitude at PO3 (LH)). B. Negative correlation (rho $=-0.43$ ) between GP recognition and $\mathrm{RH}$ lateralization score for letters (difference between amplitude at $\mathrm{O} 2$ (RH) and amplitude at $\mathrm{O} 1(\mathrm{LH})$ ).

objects and, in order to maintain periodicity, if they generalize this response across the majority of the widely variable face images presented. Moreover, the face categorization response identified in this paradigm is not accounted for by low-level visual cues such as differences in amplitude spectrum between faces and objects (see Rossion et al., 2015).

Five-year-old children's robust generic face categorization response may not appear surprising, given the behavioral evidence suggesting that preschool children are able to perform complex object categorizations in explicit tasks (e.g., Bornstein and Arterberry, 2010). However, there is, to our knowledge, very little data on generic face categorization (often referred to as "face detection") in children. Among the few behavioral observations, Carbon et al. (Carbon et al., 2013) found that explicit detection of faces in ambiguous (two-tone) Mooney figures was almost adult-like in young children ( $86 \%$ in $2-5$ year old rising to $95 \%$ in $6-10$ years old), but this is a very different task than what is evaluated in the present study. Here, our results show that five-year-old children are able to categorize widely variable images of faces automatically, i.e. without explicit instruction to do so, and extremely rapidly, i.e. at a single glance: each facial image appears for about $140 \mathrm{~ms}$ in this paradigm (Fig. 1A), and is forward- and backward-masked by nonface objects.

Nevertheless, since the very same paradigm already gave clear face categorization responses in 4-6 months old infants (de Heering and Rossion, 2015), we fully expected the present observations in 5-year-old children. The unexpected result, from our point of view at least, is that the face categorization response obtained with this paradigm in 5-yearold children is not right lateralized, contrary to what has been previously observed in infants (de Heering and Rossion, 2015) and in adults (Liu-Shuang et al., 2016; Retter and Rossion, 2016; Rossion et al., 2015).

Thus, altogether, these observations support a non-linear developmental trajectory in the RH lateralization for generic categorization of faces, which was one of the possible interpretations of the discrepant findings in the literature. Indeed, right lateralization was generally found in infants and not in children, but these discrepant findings could well have been due to different approaches in the two age populations. Here, with the very same paradigm, we show that the initial right lateralized face-selective response observed in 4-6 months old infants (de Heering and Rossion, 2015) becomes bilateral between a few months and a few years of age, i.e. before formal reading acquisition. Then, between the beginning of school at age 5-6 and adulthood, further changes which may be partly related to reading acquisition occur, resulting in a right-lateralized face-selective response at adulthood (Rossion et al., 2015). In addition, the face categorization response does not only become much larger and complex between infancy and childhood (i.e., distributed over many harmonics while it was restricted to the first harmonic in infants), but it is more widely and dorsally distributed compared to the ventral occipito-temporal response found in infants and adults. These observations are further discussed below.

\subsection{Bilateralization of face-selective responses between infancy and childhood}

At this stage, we consider two factors potentially playing an important role in the change in lateralization between infancy and preschool childhood observed in the face-selective brain response.

First, infants have poor visual acuity and their visual cortex is therefore mainly exposed to low spatial frequency visual information (Boothe et al., 1985; Maurer and Lewis, 2001). A long standing perspective points to a right hemisphere advantage in processing low spatial frequencies of visual inputs (Sergent, 1982; see also Ivry and Robertson, 1998). Even though clear-cut evidence is still lacking, this factor is thought to play a key role in the dominance of the right hemisphere for face perception (Sergent, 1985, 1982). According to the hypothesis proposed by de Schonen and Mathivet (de Schonen and Mathivet, 1989), the right hemisphere may take precedence on its left counterpart due to its faster maturation rate at the time at which the first facial inputs, based on low spatial frequencies, are presented to the infant's brain. Furthermore, visual input to each eye is directed only to the contralateral hemisphere in young infants, since the corpus callosum, the main interhemispheric pathway, slowly matures between 3 months of age (Yakovlev and Lecours, 1967), up to two years (de Schonen and Bry, 1987; Le Grand et al., 2003; Liegeois et al., 2000; Salamy, 1978). Thus, it may well be that the initial selective representation of faces develops essentially in the right hemisphere, and then transfers to the left hemisphere only after myelination of the posterior part of the corpus callosum (between 3 months and a few years of age). Such a developmental scenario would account for the difference between the right lateralization of the response observed in 4-6 months old infants (de Heering and Rossion, 2015) and the bilateral response characterizing preschoolers (here), this bilateral representation leaving space for the competition with the left representation of faces to take place when children start to learn visual letters (Behrmann and Plaut, 2015; Dundas et al., 2012). In this view, the right lateralization in the selective response to faces seen in adults with the same paradigm would be observed because they have acquired an expert reading system (Dehaene et al., 2015). Further studies at different ages of reading acquisition or different levels of reading competence in adults are needed to assess this hypothesis, and the present paradigm provides a unique opportunity to do so.

A second, non-exclusive potential factor is that although young 
infants are able to perform perceptual object categorization (Quinn et al., 1993; Rakison and Oakes, 2003), they did not yet, arguably, encounter many different categories of objects in their environment. Hence, since it contrasts familiar visual patterns (i.e., faces) with unfamiliar patterns, infants' right lateralization of the face-selective response observed with this paradigm might be particularly enhanced. In contrast, 5-year-old children as tested here, have already acquired the knowledge of many different object categories, therefore the presented stimulation sequences contrast two familiar categories, i.e. faces vs. a wide range of objects (e.g., flowers, fruits, lamps, guitar,...), a factor which may contribute to their lack of $\mathrm{RH}$ lateralization. This point serves as a useful reminder that our paradigm does not measure an absolute response to faces, but a contrast, i.e. a face-selective response, where faces are contrasted to many variable categories of stimuli. Therefore the scalp topography of responses to faces also depends on how the visual system processes the other stimuli presented. It is possible that at this fast rate, there are differences between infants, children, and adults in processing not only the faces but also for the nonface base stimuli. This is actually suggested by the scalp topographies of the responses at the base rate, which are very similar between infants and young children with a central medial peak of response (around $\mathrm{Oz}$ ), even if children start to show a (non-significant) shift to the right hemisphere, while in adults it is clearly right-lateralized (Rossion et al., 2015). Note that we do not consider this as a limitation of the paradigm: the real question at stake is whether the specific representation of faces (e.g., as indexed by the FFA in fMRI, i.e. a differential response) is lateralized, and the process of interest, generic face categorization, is a differential process.

\subsection{Beyond lateralization: quantitative and qualitative response increase between infancy and childhood}

Interestingly, the selective response to faces in preschoolers is of much greater amplitude than in infants, but also much more complex: while it is essentially limited to the first harmonic at $1.2 \mathrm{~Hz}$ in infants (Fig. 1C, de Heering and Rossion, 2015), the response spreads over multiple harmonics in preschool children (Fig. 2). Moreover, the peak and distribution of the response on the scalp also differs, with a relatively focal peak at (right) occipito-temporal sites in infants (P8 channel), as well as in adults (Retter and Rossion, 2016; Rossion et al., 2015), while the bilateral face-selective response observed in children is much more widely distributed, even peaking more dorsally on parietooccipital sites (Fig. 2B).

An increase of the amplitude of the face categorization response is expected between infancy and childhood due to the maturation of the face (and object) processing systems. However, admittedly, we cannot fully exclude an increase in the magnitude of the response also due to the different lengths of stimulation sequences used (i.e., to avoid tiredness, infants were tested with shorter sequences, but were presented with more sequences on average) and a higher attention to the stimuli in children who, contrary to infants, had to perform an orthogonal task to maintain fixation.

At present, we can only conjecture about the factors leading to these qualitative differences between infancy and childhood in generic face categorization. Indeed, several changes take place at the neural level during that time of life. The skull thickens, leading to more diffusion of electrical activity and reduced amplitudes in children. Different white matter pathways, including the corpus callosum, mature and myelinate, resulting in faster and sharper responses with different components. All these factors may contribute to the differences observed between infants and preschool children.

On the one hand, the increase in the number of significant harmonics in the response can be interpreted as an increase in the complexity of the response. While in infants the response appears to mainly reflect a single, low frequency (i.e., $1.2 \mathrm{~Hz}$ ) face-selective deviation from the $6 \mathrm{~Hz}$ base rate used in the stimulation sequence, the children's face- selective response is likely to be constituted of several differential (i.e. face-selective) components, as in adults (Retter and Rossion, 2016; Rossion et al., 2015). Since waveforms with sharper edges (rise/decay faster than a sinusoid) give rise to high power in the frequency domain (Regan, 1989; Zhou et al., 2016), it could also reflect sharper or faster neural responses in children compared to infants, as a result of brain maturation, and as observed in ERPs in response to transient events (i.e., compare the slow ERPs evoked by pictures of faces and cars in infants, e.g. Peykarjou and Hoehl, 2013; to the sharper and earlier responses obtained in children to the same kind of stimuli, Kuefner et al., 2010). We could speculate that in infants, responses to faces are slower and may overlap at $1.2 \mathrm{~Hz}$, while in children responses are faster and do not overlap, giving rise in the spectral domain to a concentration of the response on the first harmonic in infants, compared to a face-selective response distributed on several harmonics in children. On the other hand, since cortical folding or gyrification is stable despite changes in brain size between infancy and childhood (Armstrong et al., 1995), the wider spread of the face-selective response over medial occipital and parietal sites in children, independently of its left lateralization, is unlikely to be due to changes in the orientation of the cortical sources with respect to the scalp. Rather, this effect may also be partly related to changes in corpus callosum maturation or to other changes in neural responses between infancy and childhood.

\subsection{The link between reading acquisition and face categorization}

Our EEG data suggest that in 5-year-old children the two hemispheres do not differ in neural specialization for face stimuli. This lack of lateralization cannot be due to a lack of sensitivity of the technique, since the exact same approach reveals a right lateralization in infants (de Heering and Rossion, 2015) and in the majority of typical adults tested (Liu-Shuang et al., 2016; Retter and Rossion, 2016; Rossion et al., 2015). This finding is in line with the lack of significantly larger faceevoked N170 in the RH than in the LH in children up to 9-12 year old, even though the pattern of right lateralization is not systematic across ERP studies (Dundas et al., 2014; Itier and Taylor, 2004b; Kuefner et al., 2010; Taylor et al., 1999). Note that such a lack of right lateralization commonly observed in children who are already proficient readers goes against a strong view of a direct influence of learning to read on face lateralization. Moreover, the children tested here are younger than the children tested with faces in previous EEG studies and, importantly, they already show a left lateralized response to alphabetic material as a group (Lochy et al., 2016).

Interestingly, across the population of children tested here, there was no significant correlation between this left lateralization of the response to letters and the right lateralization of the response to faces. Although this result does not agree with the correlation between the amplitude of the response to words in the $\mathrm{LH}$ and that to faces in the $\mathrm{RH}$ in 7-12-year-old children (Dundas et al., 2014), we note that the reverse correlation has also been reported (Li et al., 2013), and that other studies also failed to find significant correlations between the two responses (in adults: fMRI, Davies-thompson et al., 2016; Pinel et al., 2014). Moreover, there was no relationship between word and face lateralization as assessed by behavioral performance for hemifield displays in older children and teenagers (Dundas et al., 2012). Some of these discrepancies might stem from the variability in age ranges tested across studies. In our study, children were preschoolers of 5 years of age, and although we clearly showed left lateralization for letters, the level of processing at this stage is still a "coarse orthographic" processing. This means that the reading system will still change and strengthen its specialization for recognition of letter strings and words, becoming sensitive to factors relative to lexicality (e.g., words vs pseudowords -which the 5 years old did not distinguish), frequency or familiarity of strings, etc. Thus, one cannot exclude that these changes have an impact on processing of other visual categories like faces at an older age, and that it is very likely that testing older children (7-12 
years old) catches a complete different stage of visual processing that could be linked to reading acquisition. Finally, it remains possible that the observed changes in lateralization for face processing would not be solely due to reading acquisition, but also to other developmental phenomena such as increased tuning for faces in the right hemisphere and neuronal pruning in the left hemisphere, that would suppress redundant connections for face processing (Zhu et al., 2016). Disentangling these hypotheses would require testing children' face selective response at different ages, namely before any letter knowledge (toddlers between 6 months of age and 4-5 years old), at the beginning of schooling (7 years old), and when reading has already reached good fluency level (9-10 years old). The paradigm used in the present study offers this opportunity for future research.

Nevertheless, our data show a positive correlation between the prereading performance of children and the lateralization of the response to faces: the more letters known by the preschoolers, the more rightlateralized their face categorization response. This is an interesting finding, which supports the view that the right lateralization of face perception is somewhat linked to reading acquisition and competence (Behrmann and Plaut, 2013; Dehaene et al., 2015; Dundas et al., 2012). Note that this result should also be considered in caution, not only because the correlation is not very high, but also in regard of the literature. Indeed, the few studies that tested the relationship between reading abilities and face processing have provided mixed results. In 4 years old tested in fMRI (Cantlon et al., 2011), no correlation was found between performance on a face task and right hemispheric response to faces, and between symbols reading and activation for symbols in the same hemisphere. There were however negative correlations between these tasks and non-preferred categories (face task and bold response to shoes in the right; symbols naming and bold response to faces in the left hemisphere), interpreted as showing that the specialization of these regions for categories does not imply an increase of the response to the category but a decrease to other categories, which would be due to pruning. In another study comparing several age groups (7-9; 11-13; and adults), the emergence of lateralization to faces (assessed with behavioral hemifield accuracy rates) correlated, as here, with reading competence (Dundas et al., 2012). Yet, the reverse relationship has also been found: higher reading scores associated with reduced face-evoked N170 right-lateralization (Li et al., 2013). Finally, other studies did not measure reading performance, which could therefore not be related to lateralization of neural responses to faces (Dundas et al., 2014).

In summary, it is fair to say that the factors leading to the right hemispheric specialization for faces in the human adult brain remain largely unclear at present, and cannot be simply directly related to reading acquisition: early right lateralization for faces (and face-specific responses) in infants does not support this view, and the relationship between the lateralization of reading processes and face processes in children and adults remains tenuous and controversial. A major obstacle to resolve this issue is that different studies carried out in different populations rely on fundamentally different paradigms and behavioral or neural measures, not only in terms of the techniques used but also in terms of the type of contrast performed (i.e., absolute response to faces or differential response to faces vs. control stimuli; absolute response in one hemisphere or lateralization index). In this context, our study contributes to the literature by clearly and objectively isolating in preschool children the same robust generic face categorization (i.e., face-selective) response with the same fast visual periodic stimulation paradigm tested previously in 4-6 months infants and adults. This approach reveals a bilateral generic face-categorization response pointing to a non-linearity of the right hemispheric dominance for generic face categorization across development. It is therefore crucial in the future to study toddlers ( 6 months of age to 5 years old) to better understand the factors underlying the observed changes, as well as specific time-points in development where reading levels can be clearly contrasted.

In addition to the great advantage of the paradigm in terms of applicability to different populations, we should emphasize that it provides objective (i.e., frequency-defined) and highly sensitive responses, often at the level of single participants, and does not require to subtract amplitudes obtained in different conditions, as the measured EEG response in an inherent index of generic categorization for faces. Given these advantages, the FPVS-EEG approach should truly open new perspectives in the future to understand the human development of face categorization (Hoehl, 2016), and of the lateralization of brain function in general.

\section{Acknowledgements}

This work was supported by a PAI/UIAP grant PAI/33 (BELSPO), an ERC grant (facessvep 284025) and the Belgian National Fund for Scientific Research (FNRS). We thank the schools and children for their participation, and two anonymous reviewers for helpful suggestions on a previous version of this paper.

\section{References}

Armstrong, E., Schleicher, A., Omran, H., Curtis, M., Zilles, K., 1995. The ontogeny of human gyrification. Cereb. Cortex 5 (1), 56-63. http://dx.doi.org/10.1093/cercor/5. 1.56.

Behrmann, M., Plaut, D.C., 2013. Distributed circuits, not circumscribed centers, mediate visual recognition. Trends Cogn. Sci. 17 (5), 210-219. http://dx.doi.org/10.1016/j. tics.2013.03.007.

Behrmann, M., Plaut, D.C., 2015. A vision of graded hemispheric specialization. Ann. N. Y. Acad. Sci. 1359 (1), 30-46. http://dx.doi.org/10.1111/nyas.12833.

Bentin, S., Allison, T., Puce, A., Perez, E., McCarthy, G., 1996. Electrophysiological Studies of Face Perception in Humans. J. Cogn. Neurosci. 8 (6), 551-565.

Boothe, R., Dobson, V., Teller, D., 1985. Postnatal development of vision in human and nonhuman primates. Annu. Rev. Neurosci. 8, 495-545. http://dx.doi.org/10.1146/ annurev.ne.08.030185.002431.

Bornstein, M.H., Arterberry, M.E., 2010. The development of object categorization in young children: hierarchical inclusiveness, age, perceptual attribute, and group versus individual analyses. Dev. Psychol. 46 (2), 350-365. http://dx.doi.org/10. 1037/a0018411.

Braddick, O.J., Wattam-Bell, J., Atkinson, J., 1986. Orientation-specific cortical responses develop in early infancy. Nature 320 (17), 617-619. http://dx.doi.org/10.1038/ $320617 \mathrm{a} 0$.

Brainard, D.H., 1997. The Psychophysics Toolbox. Spatial Vision 10 (4), 433-436(Retrieved from 〈http://www.scopus.com/inward/record.url?eid=2-s2.00030612822\&partnerID $=$ tZOtx3y1〉).

Bukowski, H., Dricot, L., Hanseeuw, B., Rossion, B., 2013. Cerebral lateralization of facesensitive areas in left-handers: only the FFA does not get it right. CortexJ. Devot. Study Nerv. Syst. Behav. 49 (9), 2583-2589. http://dx.doi.org/10.1016/j.cortex. 2013.05.002.

Cantlon, J.F., Pinel, P., Dehaene, S., Pelphrey, K.A., 2011. Cortical representations of symbols, objects, and faces are pruned back during early childhood. Cereb. Cortex 21 (1), 191-199. http://dx.doi.org/10.1093/cercor/bhq078.

Carbon, C.C., Grüter, M., Grüter, T., 2013. Age-dependent face detection and face categorization performance. PLoS One 8 (10), 1-7. http://dx.doi.org/10.1371/journal. pone.0079164.

Corballis, M.C., 1991. The Lopsided Ape. Oxford University, New York: NY.

Corballis, M.C., 2009. The evolution and genetics of cerebral asymmetry. Philos. Trans. R. Soc. Lond. B: Biol. Sci. 364 (1519), 867-879. http://dx.doi.org/10.1098/rstb.2008. 0232 .

Davidson, R.J., Hugdahl, K., 1995. In: Davidson, R.J., Hugdahl, K. (Eds.), Brain Asymetry. The MIT pr, Cambridge, MA.

Davies-Thompson, J., Tashakkor, A.Y., Barton, J.J.S., 2016. The relationship between visual word and face processing lateralization in the fusiform gyri: A cross-sectional study. https://doi.org/10.1016/j.brainres.2016.05.009.

Davies-Thompson, J., Pancaroglu, R., Barton, J., 2014. Acquired prosopagnosia: structural basis and processing impairments. Front. Biosci. (Elite Ed.) 6, 159-174. http:// dx.doi.org/10.1111/evo.12416.This.

Dehaene, S., Pegado, F., Braga, L.W., Ventura, P., Nunes Filho, G., Jobert, A., Cohen, L., 2010. How learning to read changes the cortical networks for vision and language. Science 330 (6009), 1359-1364. http://dx.doi.org/10.1126/science.1194140.

Dehaene, S., Cohen, L., Morais, J., Kolinsky, R., 2015. Illiterate to literate: behavioural and cerebral changes induced by reading acquisition. Nat. Publ. Group 16 (4), 234-244 https://doi.org/10.1038/nrn3924.

Dundas, E.M., Plaut, D.C., Behrmann, M., 2012. The joint development of hemispheric lateralization for words and faces. J. Exp. Psychol. Gen. 142 (2), 348-358. http://dx. doi.org/10.1037/a0029503.

Dundas, E.M., Plaut, D.C., Behrmann, M., 2014. An ERP investigation of the co-development of hemispheric lateralization of face and word recognition. Neuropsychologia 61 (1), 315-323. http://dx.doi.org/10.1016/j.neuropsychologia.2014.05.006.

Dundas, E.M., Plaut, D.C., Behrmann, M., 2015. Variable left-hemisphere language and orthographic lateralization reduces right-hemisphere face lateralization. J. Cogn. Neurosci. 27 (5), 913-925. http://dx.doi.org/10.1162/jocn. 
Frässle, S., Paulus, F.M., Krach, S., Jansen, A., 2016. Test-retest reliability of effective connectivity in the face perception network. Hum. Brain Mapp. 37 (2), 730-744. http://dx.doi.org/10.1002/hbm.23061.

George, F., Pech-Georgel, C., 2006. BELO Batterie d'Evaluation de la Lecture et de l'Orthographe. SOLAL, Marseille.

Gilbert, C., Bakan, P., 1973. Visual asymmetry in perception of faces. Neuropsychologia 11 (3), 355-362. http://dx.doi.org/10.1016/0028-3932(73)90049-3.

Gliga, T., Dehaene-Lambertz, G., 2007. Development of a view-invariant representation of the human head. Cognition 102 (2), 261-288. http://dx.doi.org/10.1016/j. cognition.2006.01.004.

Güntürkün, O., Diekamp, B., Manns, M., Nottelmann, F., Prior, H., Schwarz, A., Skiba, M., 2000. Asymmetry pays: visual lateralization improves discrimination success in pigeons. Curr. Biol. 10. http://dx.doi.org/10.1016/S0960-9822(00)00671-0.

de Haan, M., Nelson, C.A., 1999. Brain activity differentiates face and object processing in 6-month-old infants. Dev. Psychol. 35 (4), 1113-1121. http://dx.doi.org/10.1037/ 0012-1649.35.4.1113.

de Haan, M., Pascalis, O., Johnson, M.H., 2002. Specialization of neural mechanisms underlying face recognition in human infants. J. Cogn. Neurosci. 14, 199-209. http://dx.doi.org/10.1162/089892902317236849.

Hecaen, H., Angelergues, R., 1962. Agnosia for faces (prosopagnosia). Arch. Neurol. 7 (2), 92-100. http://dx.doi.org/10.1001/archneur.1962.04210020014002.

de Heering, A., Rossion, B., 2015. Rapid categorization of natural face images in the infant right hemisphere. eLife 4, 1-14. http://dx.doi.org/10.7554/eLife.06564.

Hillger, L. a., Koenig, O., 1991. Separable mechanisms in face processing: evidence from hemispheric specialization. J. Cogn. Neurosci. 3 (1), 42-58. http://dx.doi.org/10. 1162/jocn.1991.3.1.42.

Hoehl, S., 2016. The development of category specificity in infancy - what can we learn from electrophysiology? Neuropsychologia. http://dx.doi.org/10.1016/j. neuropsychologia.2015.08.021.

Hoehl, S., Peykarjou, S., 2012. The early development of face processing??? What makes faces special? Neurosci. Bull. 28 (6), 765-788. http://dx.doi.org/10.1007/s12264012-1280-0.

Itier, R.J., Taylor, M.J., 2004a. Effects of repetition and configural changes on the development of face recognition processes. Dev. Sci. 7 (4), 469-487. http://dx.doi.org/ 10.1111/j.1467-7687.2004.00367.x.

Itier, R.J., Taylor, M.J., 2004b. Face recognition memory and configural processing: a developmental ERP study using upright, inverted, and contrast-reversed faces. J. Cogn. Neurosci. 16 (3), 487-502. http://dx.doi.org/10.1162/089892904322926818.

Ivry, R., Robertson, L.C., 1998. The Two Sides of Perception. MIT Press, Cambridge, MA.

Jonas, J., Jacques, C., Liu-Shuang, J., Brissart, H., Colnat-Coulbois, S., Maillard, L., Rossion, B., 2016. A face-selective ventral occipito-temporal map of the human brain with intracerebral potentials. Proc. Natl. Acad. Sci. USA 113 (28), E4088-E4097. http://dx.doi.org/10.1073/pnas.1522033113.

Kanwisher, N., McDermott, J., Chun, M.M., 1997. The fusiform face area: a module in human extrastriate cortex specialized for face perception. J. Neurosci.: Off. J. Soc. Neurosci. 17 (11), 4302-4311. http://dx.doi.org/10.1098/Rstb.2006.1934.

Kolb, B., Milner, B., Taylor, L., 1983. Perception of faces by patients with localized cortical excisions. Can. J. Psychol./Rev. Can. Psychol. 37 (1), 8-18. http://dx.doi.org/ 10.1037/h0080697.

Kuefner, D., de Heering, A., Jacques, C., Palmero-Soler, E., Rossion, B., 2010. Early visually evoked electrophysiological responses over the human brain (P1, N170) show stable patterns of face-sensitivity from 4 years to adulthood. Front. Hum. Neurosci. 3, 67. http://dx.doi.org/10.3389/neuro.09.067.2009.

Le Grand, R., Mondloch, C.J., Maurer, D., Brent, H.P., 2003. Expert face processing requires visual input to the right hemisphere during infancy. Nat. Neurosci. 6 (10), 1108-1112. http://dx.doi.org/10.1038/nn1121.

Levy, J., Trevarthen, C., Sperry, R.W., 1972. Perception of bilateral chimeric figures following hemispheric deconnexion. Brain 95 (1), 61-78. http://dx.doi.org/10.1093/ brain/95.1.61.

Lhermitte, F., Chain, F., Escourolle, R., Ducarne, B., Pillon, B., 1972. Anatomical study of a case of prosopagnosia. Rev. Neurol. 126 (5), 329-346.

Li, S., Lee, K., Zhao, J., Yang, Z., He, S., Weng, X., 2013. Neural competition as a developmental process: early hemispheric specialization for word processing delays specialization for face processing. Neuropsychologia 51 (5), 950-959. http://dx.doi. org/10.1016/j.neuropsychologia.2013.02.006.

Liegeois, F., Bentejac, L., De Schonen, S., 2000. When does inter-hemispheric integration of visual events emerge in infancy? A developmental study on 19- to 28-month-old infants. Neuropsychologia 38 (10), 1382-1389. http://dx.doi.org/10.1016/S00283932(00)00041-5.

Liu-Shuang, J., Norcia, A.M., Rossion, B., 2014. An objective index of individual face discrimination in the right occipito-temporal cortex by means of fast periodic oddball stimulation. Neuropsychologia 52, 57-72. http://dx.doi.org/10.1016/j. neuropsychologia.2013.10.022.

Liu-Shuang, J., Torfs, K., Rossion, B., 2016. An objective electrophysiological marker of face individualisation impairment in acquired prosopagnosia with fast periodic visual stimulation. Neuropsychologia 83, 100-113. http://dx.doi.org/10.1016/j. neuropsychologia.2015.08.023.

Lochy, A., Van Belle, G., Rossion, B., 2015. A robust index of lexical representation in the left occipito-temporal cortex as evidenced by EEG responses to fast periodic visual stimulation. Neuropsychologia 66, 18-31. http://dx.doi.org/10.1016/j. neuropsychologia.2014.11.007.

Lochy, A., Van Reybroeck, M., Rossion, B., 2016. Left cortical specialization for visual letter strings predicts rudimentary knowledge of letter-sound association in preschoolers. Proc. Natl. Acad. Sci. USA Early Ed. 1-6. http://dx.doi.org/10.1073/pnas. 1520366113.

Maurer, D., Lewis, T.L., 2001. Visual acuity: the role of visual input in inducing postnatal change. Clin. Neurosci. Res. 1 (4), 239-247. http://dx.doi.org/10.1016/S15662772(01)00010-X.

Meadows, J.C., 1974. The anatomical basis of prosopagnosia. J. Neurol. Neurosurg. Psychiatry 37 (5), 489-501. http://dx.doi.org/10.1136/jnnp.37.5.489.

Monzalvo, K., Fluss, J., Billard, C., Dehaene, S., Dehaene-lambertz, G., 2012. Cortical networks for vision and language in dyslexic and normal children of variable socioeconomic status. NeuroImage 61 (1), 258-274. http://dx.doi.org/10.1016/j. neuroimage.2012.02.035.

Norcia, A.M., Tyler, C.W., Hamer, R.D., 1988. High visual contrast sensitivity in the young human infant. Investig. Ophthalmol. Vis. Sci. 29 (1), 44-49.

Norcia, A.M., Appelbaum, L.G., Ales, J.M., Cottereau, B.R., Rossion, B., 2015. The steadystate visual evoked potential in vision research: a review. J. Vis. 15 (6), 1-46 https:// doi.org/10.1167/15.6.4.

Otsuka, Y., 2014. Face recognition in infants: a review of behavioral and near-infrared spectroscopic studies. Jpn. Psychol. Res. 56 (1), 76-90. http://dx.doi.org/10.1111/ jpr.12024.

Otsuka, Y., Nakato, E., Kanazawa, S., Yamaguchi, M.K., Watanabe, S., Kakigi, R., 2007. Neural activation to upright and inverted faces in infants measured by near infrared spectroscopy. NeuroImage 34 (1), 399-406. http://dx.doi.org/10.1016/j. neuroimage.2006.08.013.

Peykarjou, S., Hoehl, S., 2013. Three-month-olds' brain responses to upright and inverted faces and cars. Dev. Neuropsychol. 38 (4), 272-280. http://dx.doi.org/10.1080/ 87565641.2013.786719.

Pinel, P., Lalanne, C., Bourgeron, T., Fauchereau, F., Poupon, C., Artiges, E., Dehaene, S., 2014. Genetic and environmental influences on the visual word form and fusiform face areas. Cereb. Cortex 1-16. http://dx.doi.org/10.1093/cercor/bhu048.

Quinn, P.C., Eimas, P.D., Rosenkrantz, S.L., 1993. Evidence for representations of perceptual similar natural categories by 3 and 4 month old infants. Perception 22 (4), 463-475. http://dx.doi.org/10.1068/p220463.

Rakison, D.H., Oakes, L.M., 2003. In: Rakison, D.H., Oakes, L.M. (Eds.), Early Category and Concept Development: Making Sense of the Blooming Buzzing Confusion. Oxford University Press, New York: NY.

Regan, D., 1966. An effect of stimulus colour on average steady-state potentials evoked in man. Nature 210 (5040), 1056-1057. http://dx.doi.org/10.1038/2101056a0.

Regan, D., 1989. Orientation discrimination for objects defined by relative motion and objects defined by luminance contrast. Vis. Res. 29 (10), 1389-1400. http://www. scopus.com/inward/record.url? eid = 2-s2.0-0024415823\&partnerID = tZOtx3y1.

Retter, T.L., Rossion, B., 2016. Uncovering the neural magnitude and spatio-temporal dynamics of natural image categorization in a fast visual stream. Neuropsychologia 91, 9-28. http://dx.doi.org/10.1016/j.neuropsychologia.2016.07.028.

Rizzolatti, G., Umiltà, C., Berlucchi, G., 1971. Opposite superiorities of the right and left cerebral hemispheres in discriminative reaction time to physiognomical and alphabetical material. Brain 94 (3), 431-442. http://dx.doi.org/10.1093/brain/94.3.431.

Rossion, B., 2014a. Understanding face perception by means of prosopagnosia and neuroimaging. Front. Biosci. (Elite Ed.) 6, 308-317.

Rossion, B., 2014b. Understanding individual face discrimination by means of fast periodic visual stimulation. Exp. Brain Res. 232 (6), 1599-1621. http://dx.doi.org/10. 1007/s00221-014-3934-9.

Rossion, B., Jacques, C., 2011. e N170: Understanding the Time Course of Face Perception in the Human Brain 5, pp. 115-142.

Rossion, B., Hanseeuw, B., Dricot, L., 2012a. Defining face perception areas in the human brain: a large-scale factorial fMRI face localizer analysis. Brain Cogn. 79 (2), 138-157. http://dx.doi.org/10.1016/j.bandc.2012.01.001.

Rossion, B., Prieto, E.A., Boremanse, A., Kuefner, D., Van Belle, G., 2012b. A steady-state visual evoked potential approach to individual face perception: effect of inversion, contrast-reversal and temporal dynamics. NeuroImage 63 (3), 1585-1600. http://dx. doi.org/10.1016/j.neuroimage.2012.08.033.

Rossion, B., Torfs, K., Jacques, C., Liu-Shuang, J., 2015. Fast periodic presentation of natural images reveals a robust face-selective electrophysiological response in the human brain. J. Vis. 15 (1), 18. http://dx.doi.org/10.1167/15.1.18.

Salamy, A., 1978. Commissural transmission: maturational changes in humans. Science 200 (4348), 1409-1411. http://dx.doi.org/10.1126/science.208144.

de Schonen, S., Bry, I., 1987. Interhemispheric communication of visual learning: a developmental study in 3-6-month old infants. Neuropsychologia 25 (4), 601-612. http://dx.doi.org/10.1016/0028-3932(87)90051-0.

de Schonen, S., Mathivet, E., 1989. First come, first served: a scenario about the development of hemispheric specialization in face recognition during infancy. Cah. Psychol. Cogn./Curr. Psychol. Cogn. 9 (1), 3-44.

de Schonen, S., Mathivet, E., 1990. Hemispheric asymmetry in a face discrimination task in infants. Child Dev. 61 (4), 1192-1205. http://dx.doi.org/10.2307/1130887.

de Schonen, S., Gil de Diaz, M., Mathivet, E., 1986. Hemispheric asymetry in face pro cessing in infancy. In: Ellis, H.D., Jeeves, M.A., Newcombe, F., Young, A. (Eds.), Aspects of Face Processing. Martinus Nijhof Publilshers, Dordrecht.

Sergent, J., 1982. The cerebral balance of power: confrontation or cooperation? J. Exp. Psychol.: Hum. Percept. Perform. 8 (2), 253-272. http://dx.doi.org/10.1037/00961523.8.2.253.

Sergent, J., 1985. Influence of task and input factors on hemispheric involvement in face processing. J. Exp. Psychol. Hum. Percept. Perform. 11 (6), 846-861. http://dx.doi. org/10.1037/0096-1523.11.6.846.

Sergent, J., Signoret, J.L., 1992. Varieties of functional deficits in prosopagnosia. Cereb. Cortex 2 (5), 375-388. http://dx.doi.org/10.1093/cercor/2.5.375.

Sergent, J., Ohta, S., MacDonald, B., 1992. Functional neuroanatomy of face and object processing. A positron emission tomography study. Brain 115 (Pt 1), 15-36. http:// dx.doi.org/10.1093/brain/115.1.15.

Taylor, M.J., McCarthy, G., Saliba, E., Degiovanni, E., 1999. ERP evidence of developmental changes in processing of faces. Clin. Neurophysiol. 110 (5), 910-915. http:// 
dx.doi.org/10.1016/S1388-2457(99)00006-1.

Yakovlev, P.I., Lecours, A.-R., 1967. The myelogenetic cycles of regional maturation of the brain. Reg. Dev. Brain Early Life 3-70.

Zhou, H., Melloni, L., Poeppel, D., Ding, N., 2016. Interpretations of frequency domain analyses of neural entrainment: periodicity, fundamental frequency, and harmonics.
Front. Hum. Neurosci. 10, 1-8. http://dx.doi.org/10.3389/fnhum.2016.00274.

Zhu, X., Bhatt, R.S., Joseph, J.E., 2016. Pruning or tuning ? Maturational profiles of face specialization during typical development, 2, pp. 1-19. https://doi.org/10.1002/ brb3.464. 